Only if some imaginable observation could refute it is it testable and only then can it be scientific.

Popper's ideas encourage us not to fear or avoid error or criticism for it is by this means that we learn and expand our knowledge. We are too readily programmed to resent criticism, and yet, an acceptance of it allows the realisation that error provides us with the opportunity to improve things. The man who fights criticism out of concern to maintain his position is clinging to non-growth; an idea one might expect would appeal to analysts.

I think Dr Mathers should view Karl Popper's theory with less paranoid dismissiveness as much of what he wrote on the subject acknowledges the limitation of our knowledge and understanding and he accepted the potential contribution psycho-analysis may make. It is worth remembering that he was one of the critics of the logical positivists who were so keen to destroy metaphysics.

It is ironic that Dr Mathers' last paragraph should contain sentiments similar to those of Popper. I am sure he would approve of "keeping one's mind open" and "question constantly our own hypotheses". Certainly, he never suggested that "levels of explanation unfamiliar to us" were nonsense, only that they were non-science.

I am not a supporter of psycho-analysis and do not feel analysts should view Karl Popper as their prime enemy; they will not strengthen the validity of their concepts by decrying his ideas.

\section{Royal Liverpool Hospital}

D. N. ANDERSON

Liverpool

\section{REFERENCES}

'POPPER, K. R. (1963) Conjectures and Refutations: The Growth of Scientific Knowledge. London: Routledge \& Kegan Paul.

2 _- - (1971) In Modern British Philosophy (ed Bryan Magee) London: Secker \& Warburg.

3 _ - (1968) The Logic of Scientific Discovery, 2nd edition. London: Hutchinson. (Translation of Logik der Forschung. Vienna, 1934).

\section{Family therapy?}

\section{DeAR SiRS}

Dr Macilwain's psychodynamic formulation (Bulletin, August 1986, 10, 211-212) of the administrator (father), doctor (mother), patient (child) conflict rang true for me. I spent two years on a medical staff committee and although I felt that because of my rotational post I would not have to live with many of the decisions and would remain distant from the heat, I found myself being drawn into family mythology usually as a complaining mother. I understand that this is a common trap for the inexperienced marital therapist.

Could we have a conductor/facilitator for these meetings rather than a chairman? Should it be conjoint therapy i.e. doctor and administrator as joint therapists?
If we can accept that the common focus is the children, and that they need both of us, perhaps we can accept that it is the marriage that needs adjusting.

South Western Hospital

DONALd F. BERMingham

London SW9

\section{Mother and baby units}

\section{Dear Sirs}

We were interested to read the article by Kumar and colleagues (Bulletin, July 1986, 10, 169-172) in which the important issue of the status of the babies admitted to Mother and Baby Units is raised.

In common with many other psychiatric units, this hospital has now set aside rooms in two of the admission wards which can function as Mother and Baby Units. We have found that the best solution for the baby is for he/she to remain under the care are of the referring GP who has then agreed to provide the service that he or she would provide at home. The advantages of this are:

(1) Psychiatrists, both consultants and trainees, are not called upon to make decisions about the management of the relatively normal problems that arise with small children. This is particularly important when trainees in psychiatry vary enormously in their experience of neo-natal medicine.

(2) This process allows the normal community service of Health Visitor and Community mid-wife to see the mother during her illness and gain understanding of her experiences at that time.

(3) The opportunity for these people to see the mother in hospital gives an opportunity to de-mystify and destigmatise mental illness, and importantly, closer liaison between the different Health Service professionals involved.

In conclusion, we were astonished to hear that only three hospitals regularly called upon the community psychiatric nurse to see their patients at home. In this District it would be very rare indeed for such patients not to receive CPN support after and indeed frequently before admission.

TIMOTHY C. JERRAM Paul R. Jacques

High Royds Hospital

Menston, Ilkley

West Yorkshire

\section{Mental Health Act 1983}

\section{DeAr SiRS}

Yesterday I was asked to make an alteration on a Medical Recommendation form. I was told the patient was not "of no fixed abode' but was 'address unknown'! Is this a record?

Ealing Hospital

JACK STEINERT 